\title{
Specialized Epithelial Cell
}

National Cancer Institute

\section{Source}

National Cancer Institute. Specialized Epithelial Cell. NCI Thesaurus. Code C13006.

A cell that covers the surface of the body and lines its cavities that has a specific function to perform. 